\title{
KARAKTERISTIK PENDUKUNG KAPASITAS KAWASAN MINAPOLITAN BRONDONG KABUPATEN LAMONGAN
}

\author{
${ }^{1)}$ Achmad Fariq Rohman, ${ }^{2)}$ Moch. Shofwan \\ 1)2) Program Studi Perencanaan Wilayah dan Kota, Universitas PGRI Adi Buana Surabaya \\ Email : achmadfariqrohman@gmail.com
}

\begin{abstract}
Abstrak
Berdasarkan RTRW Provinsi Jawa Timur Tahun 2011-2031 tentang kawasan strategis pusat pertumbuhan baru untuk menghindari ketimpangan dari kawasan lain di Kabupaten Lamongan adalah mengembangkan kawasan minapolitan sebagai kawasan ekonomi baru pada kawasan pesisir yang bergerak dibidang perikanan. Tujuan penelitian ini adalah mengidentifikasi karakteristik pendukung kapasitas kawasan minapolitan Brondong. Metode yang digunakan dalam penelitian ini adalah deskriptif kualitatif. Teknik pengumpulan data menggunakan survei primer dan survei sekunder. Berdasarkan hasil penelitian, karakteristik pendukung kapasitas kawasan minapolitan memiliki ketinggian rata-rata 6,5 MDPL, dilalui sungai Anak Bengawan Solo, beriklim tropis, jenis tanah alluvium. Penggunaan lahan pada Kawasan Minapolitan sebagian besar lahan pertanian tanah kering semusim dengan luas $1.771 \mathrm{Ha}$ atau sebesar $66 \%$.
\end{abstract}

Kata Kunci : Karakteristik Pendukung, Kapasitas Kapasitas, Minapolitan.

\begin{abstract}
Based on the RTRW of East Java Province in 2011-2031 about the strategic area of the new growth center to avoid inequality from other regions in Lamongan Regency is to develop the minapolitan area as a new economic zone in the coastal areas engaged in fisheries. The purpose of this study is to identify the supporting characteristics of the Brondong Minapolitan area. The method used in this research is descriptive qualitative. Data collection techniques using primary surveys and secondary surveys. Based on the results of the study, the supporting characteristics of the capacity of the Minapolitan area have an average height of 6.5 MDPL, crossed by the Anak Bengawan Solo river, with a tropical climate, alluvium soil types. The use of land in the Minapolitan Area is mostly dry land agricultural season with an area of 1,771 Ha or 66\%.
\end{abstract}

Keywords : Supporting Characteristics, Capacity, Minapolitan Capacity. 


\section{PENDAHULUAN}

Indonesia memiliki potensi sumber daya alam yang melimpah untuk dimanfaatkan dalam peningkatan kesejahteraan masyarakat, pemerintah berupaya untuk mengembangkan potensi sumber daya kelautan dan perikanan melalui berbagai kebijakan salah satunya pengembangan Kawasan Minapolitan. Konsep tersebut telah ditetapkan dalam Peraturan Menteri Kelautan dan Perikanan Nomor 11 tentang Pedoman Umum Minapolitan, yang dimaksud dengan Kawasan Minapolitan adalah konsepsi pembangunan ekonomi kelautan dan perikanan berbasis kawasan berdasarkan prinsip-prinsip terintegrasi, efisiensi, berkualitas dan percepatan dan mempunyai fungsi utama ekonomi yang terdiri dari sentra produksi, pengolahan, pemasaran komoditas perikanan, pelayanan jasa, dan/atau kegiatan pendukung lainnya.

Untuk mendukung konsepsi Minapolitan maka ditetapkan melalui Keputusan Menteri Kelautan dan Perikanan Nomor 35 Tahun 2013 tentang Penetapan Kawasan Minapolitan, dimana dalam keputusan tersebut menetapkan 179 Kawasan Minapolitan pada 33 Provinsi di Indonesia. Berdasarkan peraturan tersebut Kabupaten Lamongan merupakan salah satu Kabupaten yang telah ditetapkan sebagai wilayah pengembangan Kawasan Minapolitan, salah satu wilayahnya adalah Kecamatan Brondong. Penunjukkan Kecamatan Brondong sebagai Kawasan Minapolitan juga didukung Rencana Tata Ruang Wilayah (RTRW) Kabupaten Lamongan sebagai Pusat Kegiatan Lokal Promosi (PKLp) dan Wilayah Pengembangan (WP II) dengan fungsi utama sebagai pemerintahan skala Kecamatan/lokal, pusat perdaganagan dan jasa skala regional, pusat industri besar dan strategis nasional, pusat transportasi nasional, pengembangan kawasan Minapolitan, pusat pelabuhan dan industri perikanan skala regional dan nasional, pusat kegiatan pariwisata skala regional, pusat pelabuhan barang skala regional, pusat pengembangan pendidikan, serta pengembangan kegiatan industri kerajinan rakyat, pertanian, peternakan dan pertambangan.

Kecamatan Brondong sebagai pengembangan Kawasan Minapolitan perlu adanya upaya analisis untuk memberi penilaian atau tingkat pengembangan Kawasan Minapolitan khususnya dalam karakteristik Kawasan Minapolitan Brondong. Tujuan penelitian ini adalah untuk mengidentifikasi karakteristik Kawasan Minapolitan Brondong di Kabupaten Lamongan.

\section{TINJAUAN PUSTAKA \\ Kawasan Pesisir}

Salah satu ruang lingkup kajian pembangunan wilayah adalah wilayah pesisir dan laut. Menurut Undang-Undang Republik Indonesia Nomor 27 Tahun 2007 tentang Pengolahan Wilayah Pesisir dan Pulau-Pulau Kecil adalah wilayah peralihan antara ekosistem daratan dan laut yang ditentukan oleh 12 mil batas wilayah ke arah perairan dan batas Kabupaten/Kota kearah pedalaman. Menurut Poernomosidhi (2007) merupakan interface antara kawasan laut dan darat yang saling mempengaruhi dan dipengaruhi satu sama lainnya, baik secara biogeofisik maupun sosial ekonomi.

\section{Pengolahan Wilayah Pesisir}

Wilayah pesisir diperlukan perencanaan yang matang dalam mengalokasikan sumberdaya alam, serta pada tahap perencanaan diperlukan koordinasi dan kerjasama yang baik dari sektor - sektor terkait baik pemerintah maupun masyarakat lokal. Menurut Abelshausen (2015) menyatakan bahwa pengelolaan wilayah pesisir yang berkelanjutan telah mengalami pergeseran dari pendekatan yang bersifat top-down menjadi bottom-up. Dalam masyarakat tradisional kombinasi pendekatan keduanya dianggap lebih diinginkan karena merupakan gambaran pendekatan 
partisipatif yang memungkinkan untuk berbagi pengetahuan secara langsung.

\section{Kawasan Minapolitan}

Suatu program kegiatan yang berupaya untuk mensinergiskan kegiatan produksi bahan baku, pengolahan dan pemasaran dalam satu rangkaian kegiatan besar dalam satu kawasan atau wilayah. Menurut Bungaran Saragih Menteri Pertanian periode 2000-2004 minapolitan merupakan kerangka berpikir dalam pengembangan agribisnis berbasis perikanan di suatu daerah. Minapolitan adalah wilayah yang berisi sistem agribisnis berbasis perikanan dengan penggeraknya usaha agribisnis.

\section{METODOLOGI}

\section{Metode Pengumpulan Data}

Metode pengumpulan data dilakukan dengan cara :

1) Survey primer merupakan kegiatan pengumpulan data yang dilakukan secara langsung dan memiliki tujuan untuk memperkuat keadaan sebenarnya pada lokasi penelitian. Dokumentasi adalah mengumpulkan data dengan cara mengambil data-data dari catatan, dokumentasi, administrasi yang sesuai dengan penelitian terkait dengan penelitian Kawasan Minapolitan Brondong.

2) Survei sekunder merupakan pengumpulan data dilakukan dengan cara survei instansi terkait dengan pengambilan data melalui instansi pemerintahan, maupun instansi swasta yang berkaitan dengan penelitian ini sangat dibutuhkan guna memperkuat data-data yang belum tersedia pada publikasi masyarakat.

\section{Jenis dan Sumber Data}

Berdasarkan jenis data dibagi menjadi dua yaitu :

1) Data Kuantitatif, yaitu data yang terbentuk angka. Data yang diperoleh adalah jumlah penduduk, luas wilayah penelitian, produksi perikanan, jumlah mata pencaharian penduduk, jumlah infrastruktur pendukung.

2) Data kualitatif, yaitu data yang terbentuk dalam bentuk kata-kata, kalimat. Data yang diperoleh adalah peta.

Dalam penelitian ini pengumpulan data di dapat melalui dua jenis data yaitu :

1) Data primer, sumber data yang diperoleh dari hasil penelitian langsung yaitu dokumentasi terkait Kawasan Minapolitan Brondong.

2) Data sekunder, sumber data yang diperoleh sebagai pendukung penelitian ini diperoleh dari instansi terkait yaitu BPS Kabupaten Lamongan, Dinas Kelautan dan Perikanan dan BAPPEDA.

\section{Metode Analisis Data}

Metode analisis dalam penelitian Infrastruktur Pendukung Pengembangan Kawasan Minapolitan Brondong Kabupaten Lamongan yaitu :

1. Analisis karakteristik kawasan dengan menggunakan metode analisis deskriptif kualitatif bertujuan untuk mengidentifikasi karakteristik kawasan Minapolitan Brondong Kabupaten Lamongan. Data yang diperlukan yaitu: topografi, hidrologi, geologi, klimatologi, jumlah penduduk, kepadatan penduduk, mata pencaharian, luas produksi perikanan, hasil produksi perikanan, luas wilayah dan tata guna lahan.

\section{HASIL DAN PEMBAHASAN}

Gambaran Umum Lokasi

Kecamatan Brondong adalah salah satu Kecamatan di Kabupaten Lamongan. Kecamatan Brondong terletak antara pada $112^{\circ} 17^{\prime} 01,22^{\prime \prime}-112^{\circ} 33^{\prime} 12^{\prime \prime}$ Bujur Timur dan $06^{\circ} 53^{\prime} 30,81^{\prime \prime}$ - $07^{\circ} 23^{\prime} 6^{\prime \prime}$ Lintang Selatan. Batas administrasi wilayah Kecamatan Brondong adalah :

$\begin{array}{ll}\text { Utara } & : \text { Laut Jawa } \\ \text { Barat } & \text { Kecamatan Palang } \\ & \text { Kabupaten Tuban } \\ \text { Selatan } & : \text { Kecamatan Laren dan } \\ & \text { Solokuro } \\ \text { Timur } & : \text { Kecamatan Paciran }\end{array}$




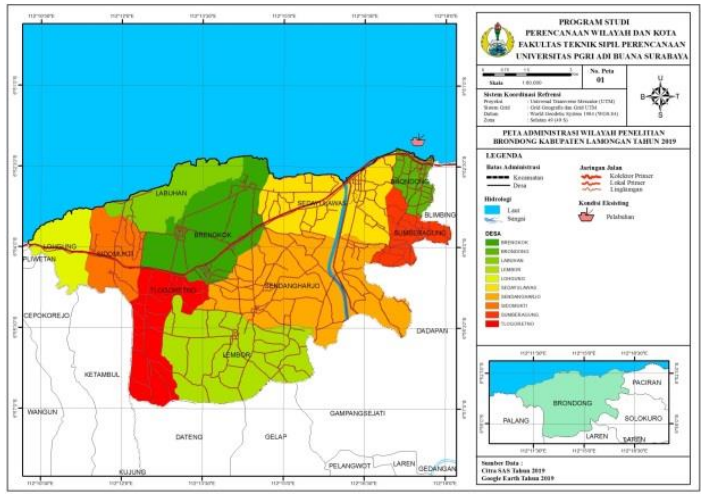

Gambar 1. Peta Administrasi Kecamatan Brondong Tahun 2019

\section{Profil Wilayah Penelitian}

Berdasarkan Peraturan Menteri Kelautan dan Perikanan Nomor 35 Tahun 2013 tentang Penetapan Kawasan Minapolitan, Peraturan Daerah Kabupaten Lamongan Nomor 15 Tahun 2011 tentang Rencana Tata Ruang Wilayah Kabupaten Lamongan Tahun 2011 - 2031 dan Keputusan Bupati Nomor 188 Tahun 2011 maka Kawasan Minapolitan Brondong didukung empat Desa dapat dilihat pada Tabel 1, untuk lebih jelasnya dapat dilihat pada Gambar 2.

Tabel 1. Kawasan Minapolitan Brondong Tahun 2019

\begin{tabular}{|c|c|c|}
\hline No & Desa & $\begin{array}{c}\text { Luas Wilayah } \\
\text { (Ha) }\end{array}$ \\
\hline 1 & Brondong & 235 \\
\hline 2 & Sedayulawas & 1.064 \\
\hline 3 & Labuhan & 643 \\
\hline 4 & Lohgung & 291 \\
\hline \multicolumn{2}{|r|}{ Jumlah } & 2.233 \\
\hline
\end{tabular}

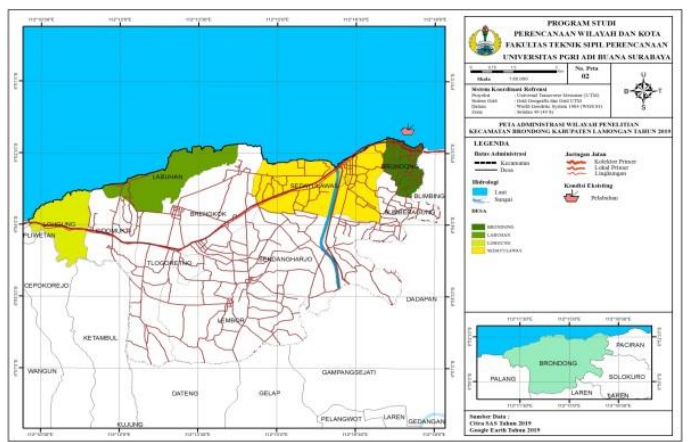

Gambar 2. Peta Kawasan Minapolitan Brondong Tahun 2019

\section{A. Analisis Karakteristik Kawasan Minapolitan Brondong}

1. Kondisi Fisik

Kondisi fisik Kawasan Minapolitan Brondong yang meliputi topografi, hidrologi, klimatologi dan geologi.

a) Topografi Kawasan Minapolitan Brondong yang meliputi Desa Lohgung, Labuhan, Sedayulawas dan Brondong mayoritas dataran rendah dengan ketinggihan rata-rata 6,5 Mdpl, dalam mendukung kegiatan perikanan maka kondisi wilayah dengan topografi rendah telah sesuai dengan Kawasan Minapolitan Brondong. Tabel 2 dan Gambar 3

Tabel 2. Topografi Minapolitan Brondong Tahun 2019

\begin{tabular}{|c|l|r|}
\hline No & \multicolumn{1}{|c|}{ Desa } & $\begin{array}{c}\text { Tinggi Rata- } \\
\text { Rata (Mdpl) }\end{array}$ \\
\hline 1 & Lohgung & 6 \\
\hline 2 & Labuhan & 6 \\
\hline 3 & Sedayulawas & 5 \\
\hline 4 & Brondong & 9 \\
\hline \multicolumn{3}{|c|}{ Rata-Rata } \\
Sumber : Hasil Analisis, 2019
\end{tabular}

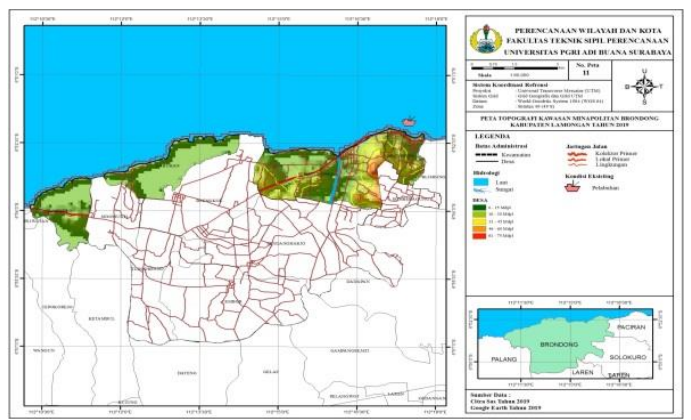

Gambar 3. Peta Topografi Minapolitan Brondong Tahun 2019

b) Hidrologi Kawasan Minapolitan Brondong ditentukan oleh kondisi geologi dan iklim, termasuk banyaknya jumlah curah hujan. Kondisi Hidrologi memiliki peran penting dalam kaitannya dengan pengembangan Kawasan Minapolitan, khususnya penentuan kebutuhan dan kapasitas air kawasan Minapolitan Brondong. Kawasan Minapolitan Brondong dilalui oleh sungai besar yaitu Anak Sungai Bengawasan Solo, dimana melewati Desa Sedayulawas serta aliran sungai bermuara ke arah laut. berdasarkan 
hasil analisis sumber air Kawasan Minapolitan Brondong sudah mencukupi guna mendukung sebagai kawasan perikanan. Gambar 4.

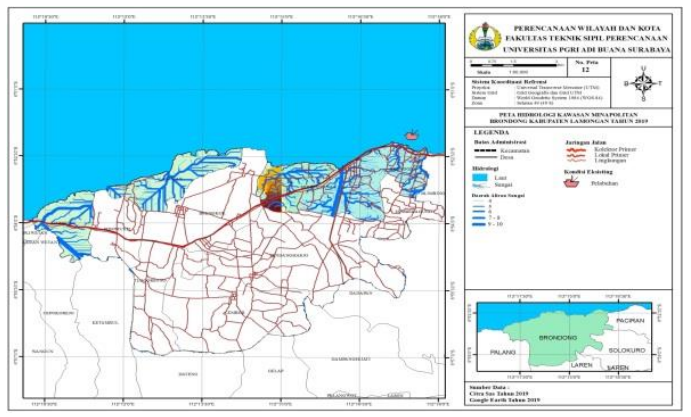

Gambar 4. Peta Hidrologi Minapolitan Brondong Tahun 2019

c) Klimatologi Kawasan Minapolitan Brondong terbagi menjadi dua yaitu musim penghujan dan kemarau dengan iklim tropis dimana tingkat kelembaban tinggi. musim penghujan berkisar pada Bulan Desember sampai April, sedangkan musim kemarau berkisar pada Bulan Mei sampai Nopember. Tabel 3. dan Gambar 5.

Tabel 3. Klimatologi Minapolitan Brondong Tahun 2019

\begin{tabular}{|l|r|r|}
\hline \multirow{2}{*}{ Bulan } & \multicolumn{2}{|c|}{$\begin{array}{c}\text { Tahun } 2019 \\
\text { Huji }\end{array}$} \\
\cline { 2 - 3 } & $\begin{array}{c}\text { Curah } \\
\text { Hujan } \\
\text { (mm) }\end{array}$ \\
\hline Januari & 9 & 384 \\
\hline Pebruari & 19 & 373 \\
\hline Maret & 9 & 145 \\
\hline April & 12 & 120 \\
\hline Mei & 5 & 71 \\
\hline Juni & 9 & 134 \\
\hline Juli & 3 & 19 \\
\hline Agustus & 0 & 0 \\
\hline September & 0 & 0 \\
\hline Oktober & 2 & 13 \\
\hline Nopember & 8 & 57 \\
\hline Desember & 11 & 128 \\
\hline Rata - rata & $\mathbf{7}$ & $\mathbf{1 2 0}$ \\
\hline Sumber : Hasil Analisis, 2019 &
\end{tabular}

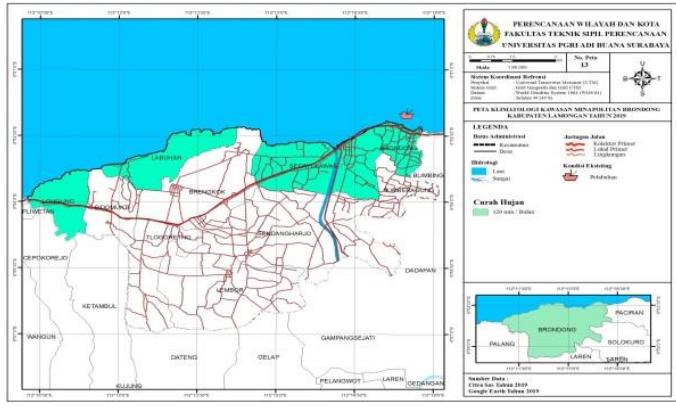

Gambar 5. Peta Klimatologi Minapolitan Brondong Tahun 2019

d) Geologi Kawasan Minapolitan Brondong didominasi didominasi jenis tanah alluvium pantai adalah sejenis tanah liat, halus dan dapat menampung air hujan yang tergenang, dengan demikian tanah jenis alluvium sesuai pada kawasan pertanian maupun perikanan. tanah jenis alluvium pada daerah perairan ataupun delta sungai yang menimbulkan endapan. Tabel 4 dan Gambar 6.

Tabel 4 Geologi Minapolitan Brondong Tahun 2019

\begin{tabular}{|c|c|c|}
\hline \\
\hline No & Desa & Jenis Tanah \\
\hline \multirow{2}{*}{1} & \multirow{2}{*}{ Lohgung } & Alluvium pantai \\
\hline & & Laterit \\
\hline \multirow{2}{*}{2} & \multirow{2}{*}{ Labuhan } & Alluvium pantai \\
\hline & & Laterit \\
\hline \multirow{6}{*}{3} & \multirow{6}{*}{ Sedayulawas } & Alluvium pantai \\
\hline & & Batulanau \\
\hline & & Batulempung \\
\hline & & Batugamping \\
\hline & & Laterit \\
\hline & & Litosol \\
\hline \multirow{4}{*}{4} & \multirow{4}{*}{ Brondong } & Alluvium pantai \\
\hline & & Laterit \\
\hline & & Batulanau \\
\hline & & Litosol \\
\hline
\end{tabular}

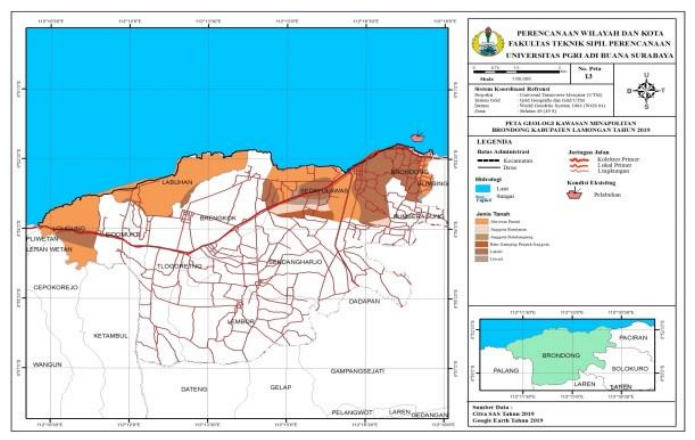

Gambar 6. Peta Geologi Minapolitan Brondong Tahun 2019 
2. Sosial Kependudukan

Sosial kependudukan sangat erat kaitannya dengan perkembangan wilayah, untuk kepadatan penduduk tertinggi berada di Desa Brondong sebesar 61 Jiwa/Ha dan jumlah penduduk menurt mata pencaharian terbanyak berada pada sektor pertanian sebesar 8.361 jiwa atau $35 \%$ dari jumlah keseluruhan. Tabel 5 dan Gambar 7.

Tabel 5. Sosial Kependudukan Minapolitan Brondong Tahun 2019

\begin{tabular}{|c|c|c|c|c|c|c|}
\hline \multirow{3}{*}{\multicolumn{4}{|c|}{$\begin{array}{l}\text { Gambar } 7 . \\
\text { Tabel 5. Sosial Kependudukan Minapolitan } \\
\text { Brondong Tahun } 2019\end{array}$}} & \multicolumn{3}{|c|}{ Brondong Tahun 2019} \\
\hline & & & & No & Penggunaan Lahan & Luas (Ha) \\
\hline & & & & 1 & Persawahan & 46 \\
\hline \multirow[b]{2}{*}{ No } & \multirow[b]{2}{*}{ Desa } & \multirow{2}{*}{$\begin{array}{l}\text { Luas } \\
\text { Wilayah } \\
\text { (Ha) }\end{array}$} & \multirow{2}{*}{$\begin{array}{l}\text { Jumlah } \\
\text { Penduduk } \\
\text { (Jiwa) }\end{array}$} & \multirow{2}{*}{$\begin{array}{l}\text { Kepadatan } \\
\text { Pendydukk } \\
\text { (Jiwa/Ha) }\end{array}$} & Tambak & 417 \\
\hline & & & & & $\begin{array}{l}\text { Pertanian tanah kering } \\
\text { semusim }\end{array}$ & 1.771 \\
\hline 1 & Lohgung & 291 & 3.962 & \multicolumn{2}{|c|}{\begin{tabular}{|l|l|}
414 & Permukiman \\
\end{tabular}} & 132 \\
\hline 2 & Labuhan & 643 & 7.781 & \multicolumn{2}{|c|}{\begin{tabular}{ll|}
512 & Hutan \\
\end{tabular}} & 180 \\
\hline 3 & Sedayulawas & 1.064 & 16.796 & \multicolumn{2}{|c|}{\begin{tabular}{l|l}
616 & Tanah Terbuka \\
\end{tabular}} & 122 \\
\hline 4 & Brondong & 234 & 14.384 & 61 & Jumlah & 2.668 \\
\hline \multicolumn{2}{|r|}{ Jumlah } & 2.232 & 42.923 & \multicolumn{2}{|c|}{ Sum 26: Hasil Analisis, 2019} & \\
\hline
\end{tabular}

Sumber : Hasil Analisis, 2019

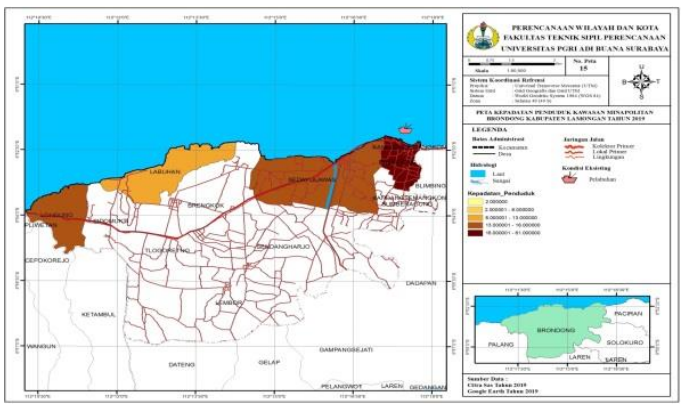

Gambar 7. Peta Kepadatan Penduduk Minapolitan Brondong Tahun 2019

3. Kondisi Ekonomi

Kondisi ekonomi memiliki peran penting dalam pertumbuhan kawasan Minapolitan Brondong yang meliputi luas produksi perikanan dan hasil produksi perikanan. Untuk luas produksi di dukung area 209 area tambak dan luas area $417 \mathrm{Ha}$. sedangkan untuk hasil produksi rata-rata 73.509 Ton/Tahun. Tabel 6.

Tabel 6. Luas Produksi Perikanan Minapolitan Brondong Tahun 2019

\begin{tabular}{|c|c|c|c|}
\hline No & Desa & $\begin{array}{c}\text { Jumlah } \\
\text { Area }\end{array}$ & $\begin{array}{l}\text { Luas } \\
\text { Area } \\
\text { (Ha) }\end{array}$ \\
\hline 1 & Lohgung & 43 & 76 \\
\hline 2 & Labuhan & 35 & 57 \\
\hline 3 & Sedayulawas & 131 & 284 \\
\hline \multicolumn{2}{|r|}{ Jumlah } & 209 & 417 \\
\hline
\end{tabular}

4. Penggunaan Lahan

Penggunaan lahan memiliki fungsi yang strategis sebagai pola pemanfaatan lahan dengan total $2.668 \mathrm{Ha}$, Kawasan Minapolitan Brondong sebagaian besar berupa pertanian tanah kering $1.771 \mathrm{Ha}$ atau $66 \%$. Tabel 7.

Tabel 7. Penggunaan Lahan Minapolitan Brondong Tahun 2019

\section{KESIMPULAN}

Berdasarkan penelitian yang dilakukan di Kecamatan Brondong sebagai berikut :

1. Kondisi fisik dilihat dari ketinggihan wilayah termasuk dataran rendah ratarata 6,5 Mdpl, dilalui Anak Sungai Bengawan Solo, beriklim tropis, didominasi jenis tanah alluvium.

2. Jumlah penduduk terbanyak berada pada Desa Sedayulawas dan Brondong serta didukung penduduk mayoritas bekerja pada bidang pertanian mencapai 8.361 jiwa atau $35 \%$.

3. Kondisi ekonomi kawasan dengan adanya kawasan perikanan dengan luas 417 Ha serta hasil produksi perikanan rata-rata 73.389 Ton/Tahun.

4. Penggunaan lahan pada Kawasan Minapolitan sebagaian besar lahan pertanian tanah kering semusim dengan luas $1.771 \mathrm{Ha}$ atau sebesar 66 $\%$.

\section{UCAPAN TERIMA KASIH}

Ucapan terimakasih ditujukan kepada Pimpinan Fakultas, Ketua Jurusan Perencanaan Wilayah dan Kota, Universitas PGRI Adi Buana Surabaya. 


\section{DAFTAR PUSTAKA}

Adisasmita, Rahardjo. 2013. Pembangunan Kawasan dan Tata Ruang. Yogyakarta: PT. Graha Ilmu.

Anonim. 2013. Keputusan Menteri Kelautan dan Perikanan No 35 tentang Penetapan Kawasan Minapolitan. Jakarta.

Anonim. 2011. Keputusan Bupati No. 188 tentang Penetapan Kawasan Minapolitan. Lamongan.

Anonim. 2012. Peraturan Provinsi Nomor 5 tentang Rencana Tata Ruang Wilayah Provinsi Jawa Timur Tahun 2011-2031. Jawa Timur.

Anonim. 2012. Peraturan Menteri Kelautan dan Perikanan No. 18 tentang Pedoman Penyusunan Rencana Induk Pengembangan Kawasan Minapolitan. Jakarta.

Anonim. 2018. Kecamatan Brondong Dalam Angka Tahun 2018. BPS.

Aswanah, Efani dan Tjahjono. 2013. Evaluasi Terhadap Implementasi Program Pengembangan Kawassan Minapolitan Perikanan Tangkap di Pelabuhan Perikanan Nusantara (PPN) Brondong Kabupaten Lamongan Jawa Timur. Jurnal ECSOFiM (Volume 1 Nomor 1). Malang.

Fatmawati, H, Y. Bambang, A, N. dan Rosyid, A. (2015). Analisis Effisiensi Tempat Pelelangan Ikan di Pelabuhan Perikanan Nusantara Brondong Kabupaten Lamongan. Jurnal Fisheries Resources Utilization Management and Technology (Volume 4 Nomor 4

Muta'ali, Lutfi. (2015). Teknik Analisis Regional. Buku Pertama. Yogyakarta: Fakultas Geografi Universitas Gajah Mada.

Rahmawati, W. Suryono, A. dan Siswidiyanto. 2015. Pengembangan Pelabuhan Perikanan Dalam Rencana Penyerapan Tenaga Kerja Masyarakat Pesisir. Jurnal Administrasi Publik (Volume 2 Nomor 2 Halaman 367-373). Malang. 